\title{
Desain Rangkaian Gate Driver Analog untuk Dual Mosfet Drivers
}

\author{
Hendi Matalata*, Rozlinda Dewi \\ Fakultas Teknik, Universitas Batanghari \\ *Corresponding email: hendi.matalata@unbari.ac.id
}

\begin{abstract}
Abstrak. Teknik pensaklaran terus berkembang hingga saat ini, diantaranya adalah sinusoidal PWM (Pulse Width Modulation), space vector PWM, current tracking PWM, harmonic elimination PWM dan lain - lain. Setiap metode memiliki kelebihan dan kekurangan, namun metode yang paling umum digunakan adalah sinusoidal PWM dan space vector PWM. PWM yang dibangkitkan menggunakan mikrokontroler maupun komponan IC analog umumnya mempunyai nilai tegangannya maksimum sebesar 5V, untuk itu dalam memperkuat gelombang PWM dibutuhkan sebuah rangkaian gate-driver, sehingga gelombang kontrol PWM tersebut mampu mengerakan IGBT/MOSFET. Pada paper ini, perancangan rangkaian gate driver menggunakan komponen IC analog yang dimulai dari pembangkitan dua buah gelombang yaitu gelombang sinusoidal dan sumber DC untuk di bandingkan (Comparator) sehingga dapat menghasilkan gelombang PWM. Kemudian gelombang PWM ini di isolasi menggunakan optocoupler dan IC driver MOSFET guna membatasi gangguan pada proses switching pada suplai daya tinggi. dari hasil penelitian, disimpulkan bahwa output gelombang kontrol PWM dari rangkaian gate-driver terisolasi dari sistem dan dapat diperuntukan pada keperluan perancangan sebuah konverter daya dan aplikasi lainnya
\end{abstract}

Kata Kunci: Comparator; PWM; Gate Driver

Abstract. Switching techniques have been continued to develop, including sinusoidal PWM, space vector PWM, current tracking $P W M$, harmonic elimination PWM and others. Each method has advantages and disadvantages, but the most commonly used methods are sinusoidal PWM and space vector PWM. PWM that is generated using a microcontroller or analog IC component generally has a maximum voltage value of $5 \mathrm{~V}$. To strengthen the PWM wave, a gate-driver circuit is needed, so that the PWM control wave is able to move the IGBT / MOSFET. On this paper, the design of gate driver circuit use An analog IC, which starts from the generation of two waves, namely a sinusoidal wave and a DC source to be compared (Comparator) so that it can produce a PWM wave. Then this PWM wave is isolated using an optocoupler and MOSFET driver IC to limit interference in the switching process on high power supplies. Based on the results, it can be cancluded PWM control wave output from the gatedriver circuit is isolated from the system intended for designing a power converter and other applications.

Keywords: Comparator; PWM; Gate Driver

\section{PENDAHULUAN}

Dewasa ini penggunaan teknologi konverter daya menjadi salah satu aspek yang sangat penting dalam sebuah perangkat peralatan listrik. Misalnya dapat ditemui pada teknologi konverter daya mengubah tegangan DC - DC dan DC - AC. Sebuah konverter DC DC dan DC - AC umumnya menggunakan rangkaian kombinasi komponen semikonduktor jenis IGBT/ MOSFET yang berfungsi sebagai komponen saklar daya, prinsip kerja komponen saklar daya umumnya menggunakan gelombang kontrol PWM (Pulse-width modulation) yang dapat dibangkitkan menggunakan mikrokontroler dan juga komponen rangkaian IC (Integrated Circuit) analog. PWM merupakan teknik pensaklaran yang menawarkan metode simpel untuk kontrol digital dan telah banyak digunakan pada aplikasi variable speed drive (VSD), power converter dan uninterupable power supply (UPS) (Datta et al, 2014). Teknik pensaklaran terus berkembang hingga saat ini, diantaranya adalah sinusoidal PWM, space vector $\mathrm{PWM}$, current tracking $\mathrm{PWM}$, harmonic elimination PWM dan lain - lain. Setiap metode memiliki kelebihan dan kekurangan, namun metode yang paling umum digunakan adalah sinusoidal PWM dan space vector PWM [2][3]. PWM yang dibangkitkan menggunakan mikrokontroler maupun komponan IC analog umumnya mempunyai nilai tegangannya maksimum sebesar $5 \mathrm{~V}$, untuk itu dalam memperkuat gelombang PWM dibutuhkan sebuah rangkaian gate-driver, sehingga gelombang kontrol PWM tersebut mampu mengerakan IGBT/MOSFET (Tarmizi, 2013 dan Vishay).

Dalam paper ini, perancangan rangkaian gate driver menggunakan komponen IC analog yang dimulai dari pembangkitan dua buah gelombang yaitu gelombang sinusoidal dan sumber DC untuk di bandingkan (Comparator) sehingga dapat menghasilkan gelombang PWM. Kemudian gelombang PWM ini di isolasi menggunakan optocoupler dan IC driver MOSFET guna membatasi gangguan pada proses switching pada suplai daya tinggi. Pada penelitian ini sebuah rangkaian gate-driver dibangun menggunakan IC Dual MOSFET Drivers MC34151 dengan isolasi optocoupler PC817. Sehingga gelombang kontrol PWM output dari rangkaian gate-driver terisolasi dari sistem. yang nantinya dapat digunakan dalam berbagai aplikasiaplikasi lainnya (Hamid, 2016). 


\section{Tinjauan Pustaka}

Rangkaian gate-driver terisolasi menurut Zheng. W, dkk (2010), beberapa kreteria yang dapat menetukan kualitas rangkaian gate-driver adalah sebagai berikut:

1. IC driver yang digunakan mampu memproteksi ganguan akibat dari proses switching.

2. Output gelombang kontrol PWM yang dihasilkan terisolasi dari sistem, sehingga arus balik pada saat switching tidak menimbulkan efek panas pada IGBT/MOSFET.

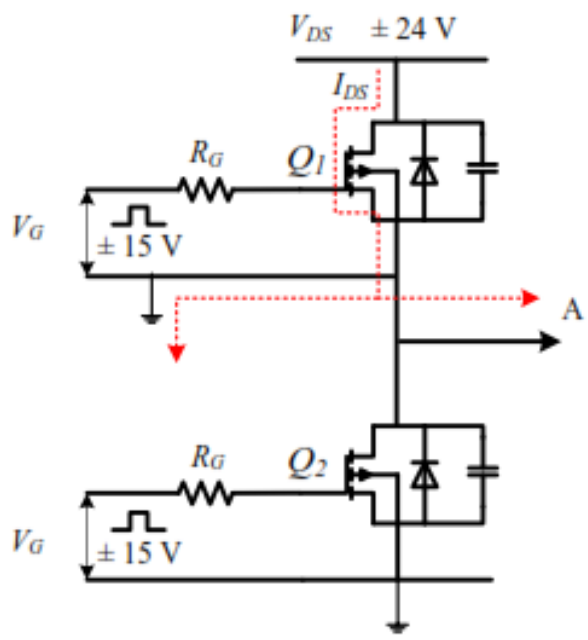

Gambar 1. Gate Driver MOSFET terisolasi (Hamid, 2016)

\section{Pulse Width Modulation (PWM)}

Untuk membangkitkan gelombang PWM menggunakan rangkaian Analog maka dibutuhkan dua buah gelombang, yaitu gelombang Reference dan gelombang Carrier. Pada proses PWM kedua gelombang ini dibandingan untuk mendapatkan kondisi ON dan kondisi OF pada sebuah gelombang PWM.

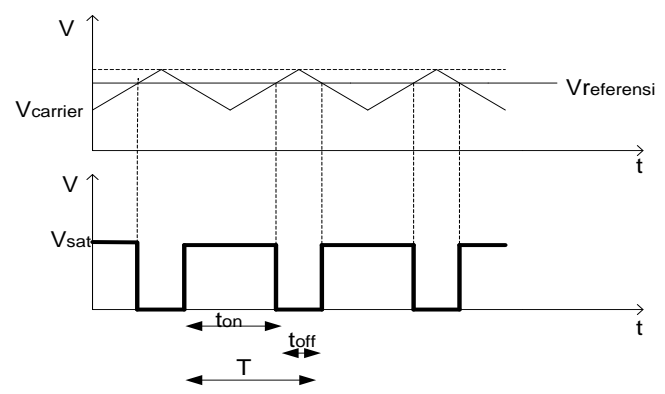

Gambar 2. Proses PWM (Mohan, 2012)

$D=\frac{t_{o n}}{\left(t_{o n}+t_{o f f}\right)}$

\section{METODE}

Pada paper perancangan Gate Driver untuk mendapatkan dua buah gelombang dengan perbedaaan pergeseran phasa maka masing-masing harus mempunyai delay agar tidak bekerja secara serentak (Hendi dan Hamid, 2016). Delay dari gelombang PWM dapat diatur pada rangkaian pembangkitan gelombang sinus, adapun blok diagram gate driver diperlihatkan pada gambar 3 dibawah.

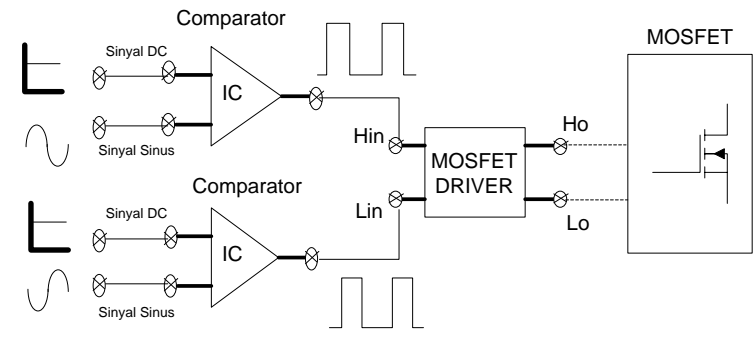

Gambar 3. Blok Diagram Gate Driver (Hendi dan Hamid, 2016)

\section{Gelombang Sinus}

Perancangan rangkaian analog untuk membangkitkan gelombang sinus umumnya menggunakan sebuah IC analog, salah satunya adalah IC LM 358 seperti diperlihatkan pada gambar 4 dibawah.

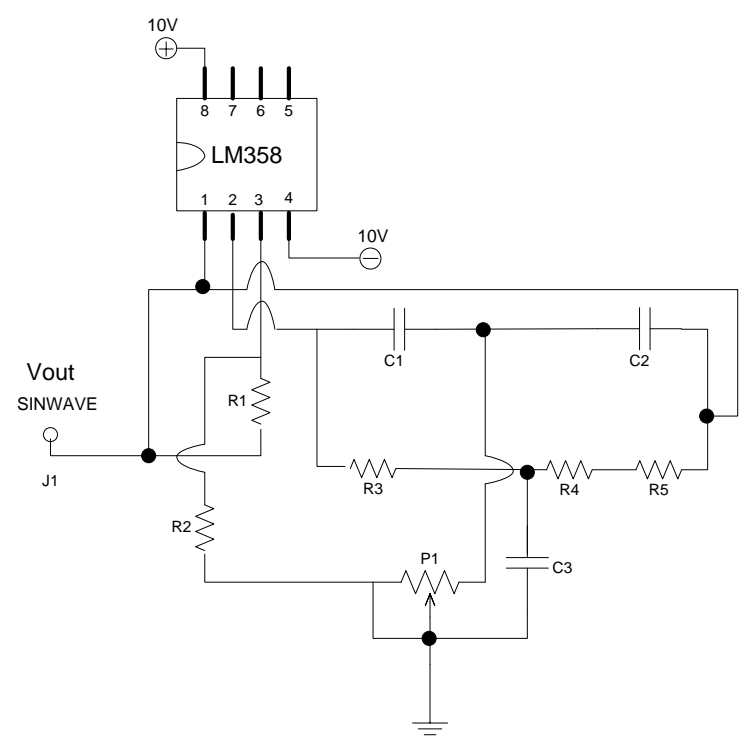

Gambar 4. Rangkaian Pembangkit Gelombang Sinus

Pada rangkaian pembangkit gelombang sinus gambar 4 diatas, untuk mendapatkan besar frekuensi 50 $\mathrm{Hz}$ diatur menggunakan potensio (P1)

\section{Phase Shift}

Karena terdapat dua buah gelombang PWM yang akan dibangkitkan maka untuk mengatur pergesaran Phasa dari salah satu gelombang PWM digunakan rangkaian phase Shift seperti diperlihatkan pada gambar 5 dibawah.

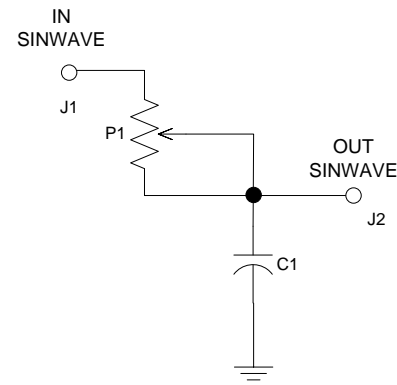

Gambar 5. Rangkaian Phase Shift 


\section{Non Inverting}

Non Inverting adalah penguat gelombang sinus yang telah dibangkitkan IC LM 358 seperti dijalaskan diatas, adapun rangkaian non inverting menggunakan IC LM 741 seperti diperlihatkan gambar 6 dibawah.

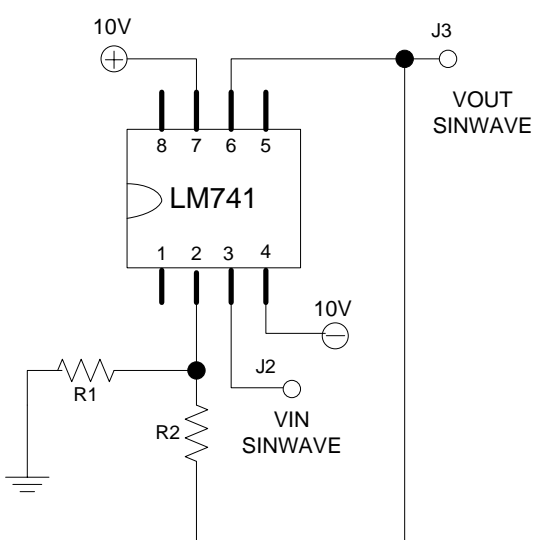

Gambar 6. Rangkaian Non Inverting

\section{Regulator DC}

Regulator DC merupakan gelombang carrier yang akan di bandingkan dengan gelombang referensi (gelombang sinus) untuk mendapatkan gelombang PWM, rangkaian regulator DC menggunakan IC LM 317.

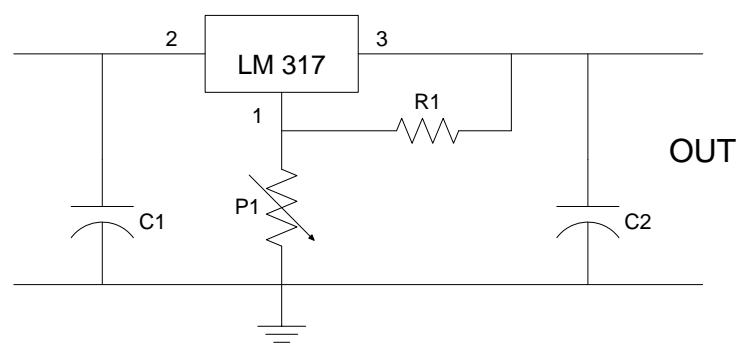

Gambar 7. Rangkaian Regulator DC

\section{Comparator}

Proses comparator untuk pembangkitan gelombang PWM menggunakan IC LM 393 yang mana pada rangkaian ini gelombag input adalah gelombang sinus dan sumber DC (regulator) adapun rangkaian comparator diperlihatkan pada gambar 8 dibawah.

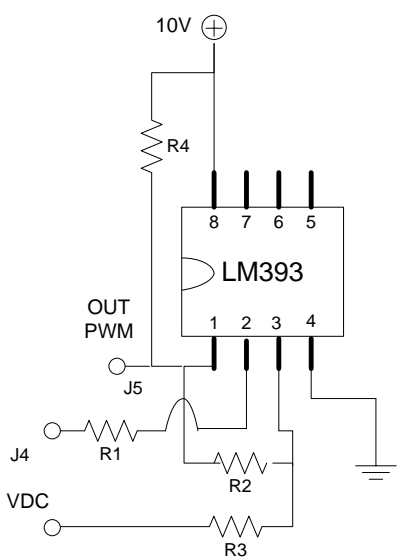

Gambar 8. Rangkaian Comparator

\section{Optocoupler}

Gelombang PWM yang dihasilkan pada rangkaian comparator kemudian di isolasi menggunakan rangkaian Optocoupler PC 817.

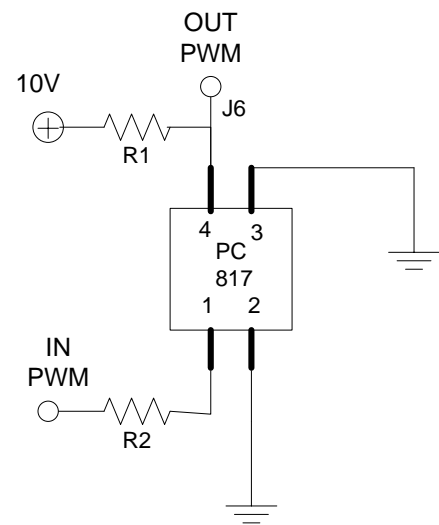

Gambar 9. Rangkaian Optocoupler

\section{Driver MOSFET}

Untuk membuat agar MOSFET bekerja maka kaki pada Gate MOSFET diberikan gelombang PWM dengan tegangan sebesar 15 Volt. Untuk itu dibutuhkan rangkaian gate driver MOSFET. Rangkaian ini menggunakan IC dual MOSFET drivers MC 34151.

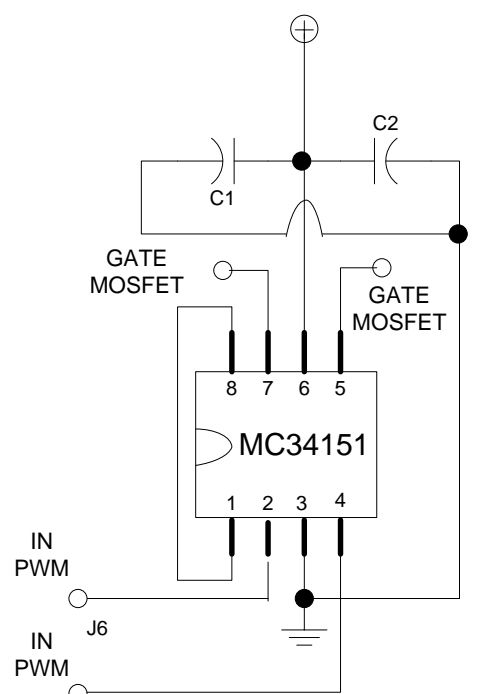

Gambar 10. Rangkaian Driver MOSFET

\section{HASIL DAN PEMBAHASAN}

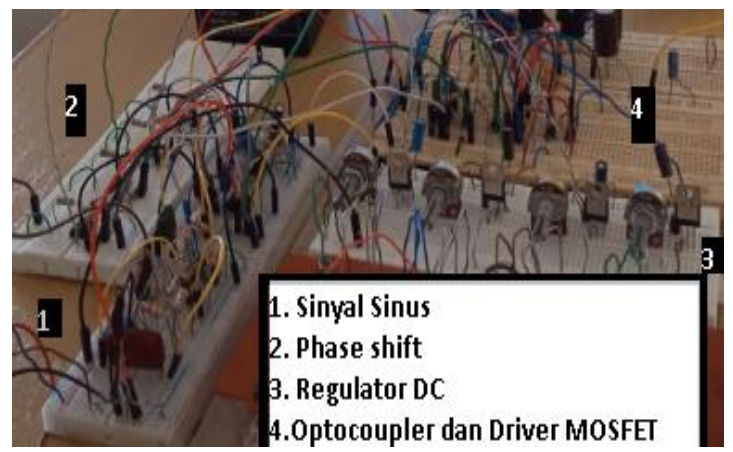

Gambar 11. Rangkaian Realisasi Gate Driver 


\section{Pengujian Rangkaian Gelombang Sinus dan Gelombang DC}

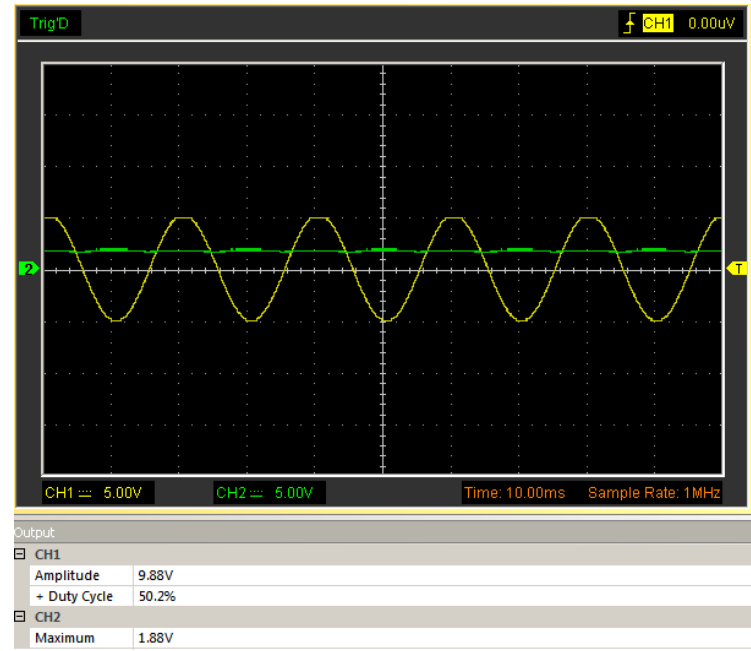

Gambar 12. Pengujian Rangkaian Comparator

Dari hasil pengujian pada gambar 12 diatas terdapat dua buah gelombang yaitu gelombang sinus yang dibangkitkan dari IC LM 358 dan gelombang DC yang dibangkitkan dari rangkaian regulator, yang mana kedua gelombang ini akan dibandingkan menggunakan IC Comparator untuk mendapatkan gelombang PWM.

\section{Pengujian Rangkaian Comparator}

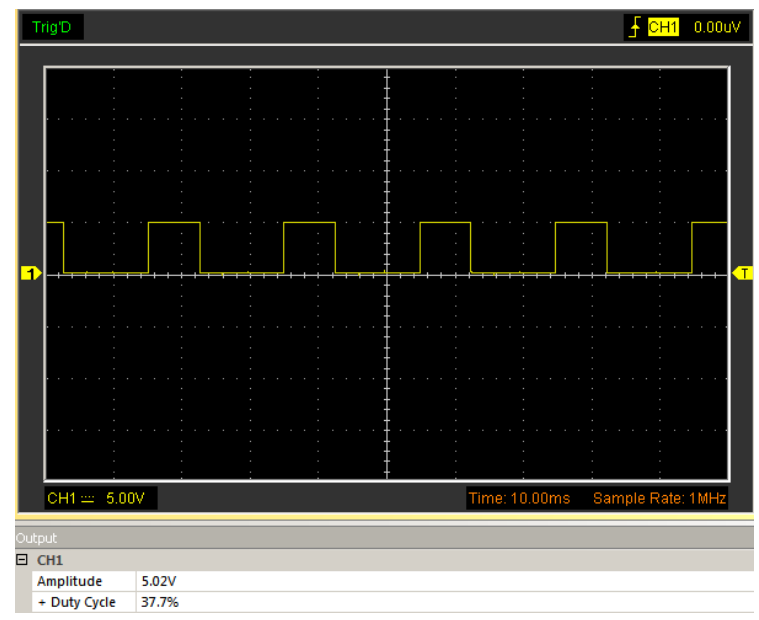

Gambar 13. Pengujian Rangkaian PWM

Hasil pengujian pada gambar 13 diatas adalah bentuk gelombang PWM yang dihasilkan dari IC comparator LM 393, yang mana gelombang PWM tersebut mempunyai amplitoudo tegangan sebesar 5 volt dan duty cycle sebesar 37,7\% dengan frekuensi $50 \mathrm{~Hz}$.

\section{Pengujian Rangkaian Gate Driver}

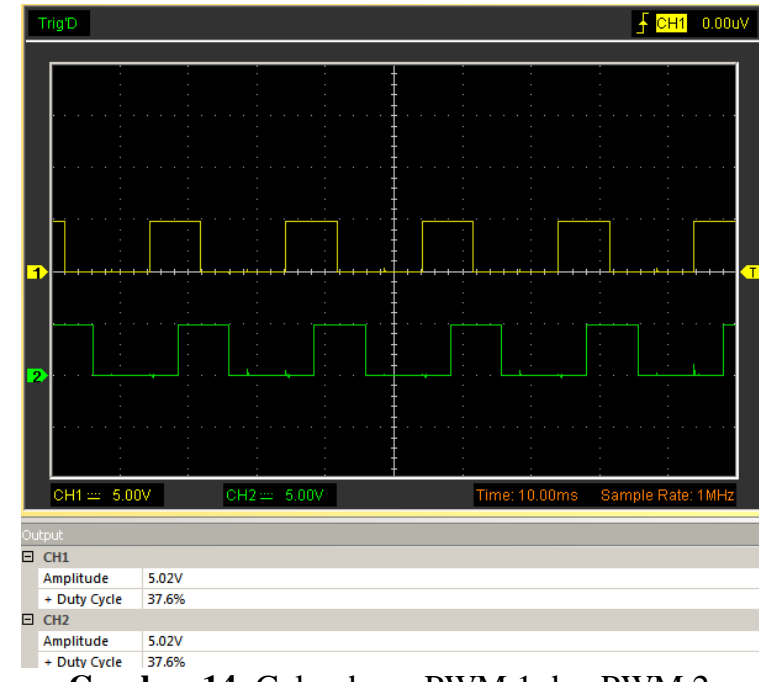

Gambar 14. Gelombang PWM 1 dan PWM 2

Dari hasil pengujaian gambar 14 diatas memperlihatkan bentuk gelombang PWM 1 dan PWM 2 yang mana masing-masing gelombang mempunyai delay sebesar 2,5 ms. Gelombang PWM 1 dibangkitkan dari gelombang sinus dan sumber DC kemudian untuk membangkitkan gelombang PWM 2 dibangkitkan kembali satu gelombang sinus kemudian di bandingkan sebagaimana proses pembangkitan gelombang PWM. Delay gelombang PWM 2 diatur dari rangkaian phasa shift seperti dijelaskan sebelumnya. Gelombang ini merupakan gate driver MOSFET diperuntukan pada kebutuhan perancangan konverter daya.

\section{SIMPULAN}

Dalam Paper ini telah dilakukan penelitian dalam perancangan 2 buah switch gate driver MOSFET yang mempunyai delay sebesar 2,5 ms yang diperuntukan pada keperluan perancangan sebuah konverter daya dan aplikasi lainnya. Penekan dalam penelitian ini adalah adanya isolasi dari blok kontrol PWM pada rangkaian daya yang menggunakan komponen saklar daya (MOSFET).

\section{DAFTAR PUSTAKA}

A. Datta, D. Mukherje, and H. Saha." A dsPIC based novel digital sinusoidal pulse-width modulation technique for voltage source inverter applications," microprocess. Microsyst., vol.38, no.7, pp.649-658, 2014.

F. and M.I. Hamid, "desain Rangkaian Gate-Driver untuk Konverter yang bekerja dengan Voltage Mode Control," J.Nas. Tek. Elektro, vol.5, no.2, p.175, 2016.

H. Matalata and M. I. Hamid,"Pengembangan Topology Inverter Multilevle Tiga Tingkat Satu Fasa Tipe Diode Clamped dengan Mereduksi Komponen Saklar Daya," J. Nas. Tek. Elektro, vol.5, no. 3, p.360, 2016.

N.MOHAN, book, 1st ed., vol.1. USA:Don Fowley, 2012. 
Tarmizi, Muyassar," Rancang Bangun Inverter SVM Berbasis Mikrokontroler PIC 18F443 untuk Sistem VSD," Jurnal Nasional Teknik Elektro, Vol.2, no.1, maret 2013.

Vishay Siliconix, data Sheet HCPL 4506. www.avagotech.com

Zheng. W., Meiying. Q., "The Application of IGBT Driver MC 33153," IEEE, 978-1-4244-7618-3, 2010. 